\title{
REDE HOTELEIRA E TURISMO EM PARINTINS: CONTRIBUIÇÕES PARA A REDE URBANA DE UMA CIDADE MÉDIA NA AMAZÔNIA ${ }^{i}$
}

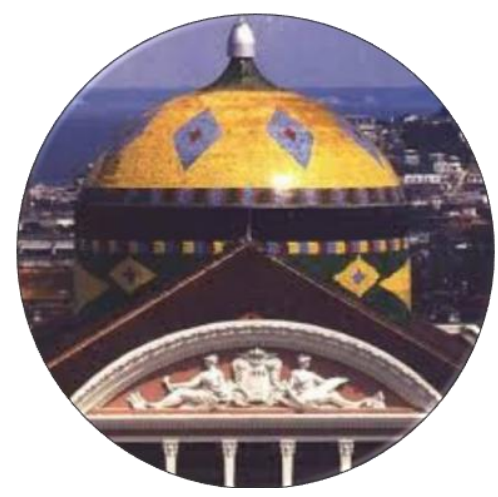

Hugo Rogério Hage Serra ${ }^{i i}$

\section{Resumo}

Este trabalho possui como fundamento a relação existente entre a atividade turística , a rede hoteleira de Parintins e sua formação espacial na condição de cidade média na Amazônia. Utiliza-se o Manual da Rede de Cidades Médias - RECIME - como condição para efetivação da pesquisa. Discutem-se os elementos que norteiam a formação de uma cidade média na Amazônia e sua relação com a atividade turística em Parintins.

Palavras-chave: Rede Hoteleira. Cidades Médias. Amazônia. Parintins.

\begin{abstract}
This work is based on the relationship between tourism activity, the hotel chain of Parintins and its spatial formation in the condition of average city in the Amazon. The Manual of the Medium Cities Network - RECIME - is used as a condition for conducting the research. We discuss the elements that guide the formation of a middle city in the Amazon and its relation with the tourist activity in Parintins.
\end{abstract}

Keywords: Hotel chain. Medium Cities. Amazon. Parintins.

\section{Introdução}

É bem sabido que a realidade das cidades médias no Brasil se torna diferente de acordo com os lugares onde elas se inserem. $\mathrm{O}$ fator histórico e as condições culturais são alguns dos elementos fundamentais para entender a formação espacial. Concorrem para isso, obviamente, a 
dinâmica intraurbana e sua relação com as particularidades econômicoregionais, como sendo elementos de análise para se entender o desenvolvimento desses espaços.

$\mathrm{Na}$ Amazônia, a realidade das cidades médias se dá a um sabor diferenciado em relação ao restante do território brasileiro. Isso se torna mais específico se evidenciarmos as diferentes sub-regiões presentes neste vasto território. Parintins é um caso a ser pensado se houver um cotejamento com outras cidades da região e, mais ainda, de outras localizadas nos mais diferentes rincões do território brasileiro.

Um dado torna-se bastante evidenciado em Parintins: a manifestação folclórica de seu festival que ocorre nos últimos dias do mês de junho. Para tanto, tal evento, que já tem dimensões internacionais, carrega consigo uma vasta reformulação do espaço para atender ao grande afluxo de pessoas que têm interesse em participar dele. Nesse sentido, são mobilizadas pessoas e infraestrutura locais para dar conta dessa "sazonalidade". Os hotéis são exemplo concreto disso, posto que sejam fixos espaciais que garantem, em tese, a acomodação das pessoas no período do festival. Por mais que haja um processo similar da rede de hotéis em Parintins em relação aos demais hotéis no Brasil e no mundo no que se refere aos períodos de alta e baixa temporada - o interessante é saber em que medida esses elementos alteram a dinâmica espacial dessa cidade, ao ponto de reestruturar a rede urbana do estado. Sendo assim, o questionamento que se segue é o de saber qual a importância de se analisar a rede hoteleira de Parintins para os estudos da rede urbana do Amazonas? Esse questionamento é fulcral e permite entender como se desenvolve a relação rede hoteleira-turismo e produção do espaço parintinense, na condição de cidade média na Amazônia, percebendo-se, ainda, o impacto gerado pela consolidação do Polo Industrial de Manaus na dinâmica intraurbana da cidade. 
Assim, pretendendo dar conta dessa empreitada, este trabalho está subdividido em três seções. A primeira delas faz breves considerações sobre o conceito de cidade média e como isso se aplica em Parintins. A segunda aplica a relação entre a atividade turística e a produção do espaço, mostrando como essa atividade depende, em toda sua complexidade, do espaço para que haja a reprodução das relações socioculturais do turismo. E, por fim, a terceira parte mostra a distribuição da rede hoteleira e de que forma esse elemento torna-se importante para a compreensão da rede urbana. Utiliza-se, ainda, como metodologia de análise o manual da RECIME (rede de cidades médias). Pretende-se com isso explicar um fragmento da realidade de Parintins - o da rede hoteleira - e sua interconexão com a rede urbana do Amazonas.

\section{Cidades médias: uma revisão do conceito e a relação com a atividade turística em Parintins.}

A discussão que envolve cidade média e turismo pode parecer, de início, uma relação um tanto quanto distante. De fato, poder-se-ia saber como essa atividade - que já é considerada por muitos como uma atividade social antes de ser econômica (CRUZ, 2001, RODRIGUES, 1999, SERRA, 2007) - tem influências diretas e indiretas na conformação de uma cidade média. Um dado analítico complicador para essa situação é pensar que o turismo pode influenciar na reorganização da rede urbana de uma cidade com aquelas características.

Não obstante a isso, entre outras discussões que vem sendo realizadas nos estudos sobre a atividade turística nos lugares é a de que esta última, por ser global e por acompanhar o ritmo frenético do atual modo de produção econômico, tende a homogeneizar os espaços. As relações pessoais teriam, portanto, um perfil parecido nos diversos lugares porque estariam sob a égide do "consumo do lugar" (CARLOS, 2002). Nesse sentido, pouco sentido faria uma opção pela cidade média como sendo um 
espaço diferenciado dos demais, no que se refere à atividade turística. Se insistirmos nas declarações feitas anteriormente, perceberíamos, antes mesmo de uma classificação de cidade média, pequena ou grande, as relações que a atividade turística imprime sobre o espaço. Porém, antes de se pensar essa relação torna-se interessante saber de que forma se concebe cidade média, no que se refere a sua análise conceitual.

Corrêa (2007), por exemplo, afirma que para a identificação de uma cidade média é necessário estabelecer uma correlação entre o tamanho demográfico, funções urbanas e a organização social. Esses elementos estariam devidamente assinalados e serviriam como suporte para o entendimento de uma rede urbana. Segundo o autor, o jogo de escalas é que define a importância de uma cidade média e também sua configuração interna. Se for pensada a partir dela em relação ao seu entorno, sua importância é mais destacada; por outro lado, se for pensada dentro de uma estrutura onde se considere a rede urbana global, sua importância será reduzida.

Para Sposito et ali (2007), um dos enfoques considerados na análise de uma cidade média é a dimensão econômica. As autoras explicam que os universos de relações sociais ocorridas ao longo dos anos mais recentes recaem, em grande medida, sobre esta dimensão, o que favorece entender suas especificidades intraurbanas e como elas respondem pelas demandas regionais. Os fluxos de ordem econômica, nesse sentido, podem, inclusive, ultrapassar a região, formando verdadeiras estruturas espaciais em rede, descaracterizando, em parte, a contiguidade do território. Esses elementos, articulados entre si, facilitam o entendimento de uma cidade média. Não obstante, deve-se respeitar o funcionamento interno das cidades como forma de se entender seus processos históricos, bem como a conjuntura internacional a qual estão submetidas.

Aproveitando-se em parte da mesma ideia defendida por Sposito (2001), Trindade Jr (2011) revela a importância de se discutir, 
anteriormente, ao conceito de cidade média, as categorias de centro e centralidade. O jogo relacional desses elementos é o que melhor define uma cidade média. Nesses termos, as atividades relacionadas aos fixos - centro e as atividades ligadas aos fluxos (SANTOS, 2004) contém e estão contidas nas cidades médias, o que terminaria por caracterizar como novos centros sub-regionais. Ainda para este autor, é importante que se faça o registro de que não são somente as dinâmicas econômicas de um território que são capazes (suficientes) de caracterizar uma cidade média e, por conseguinte, seu posicionamento dentro de uma rede urbana. Em uma região como a Amazônia, onde o processo de produção do espaço deu-se de forma "lenta" por um longo período histórico-espacial (até meados de 1960), e por outro, de forma veloz, difusa e variada - mais marcado pelos arranjos modernos de infraestrutura espacial - (após os anos 1960), a dimensão política torna-se um importante elemento para compreensão de uma cidade média na região iii. Assim, o produto da relação entre as centralidades econômicas e as centralidades políticas faz parte do processo de configuração de espaços como os das cidades médias na Amazônia.

Trindade Jr. (2011) ainda considera que não se pode confundir o conceito de cidade de porte médio com o de cidade intermediária, tampouco com o de cidade média, pois, para ele:

No primeiro caso, considera-se o patamar populacional para reconhecer tão simplesmente o tamanho demográfico das cidades. As cidades intermediárias, por sua vez, são definidas tendo em vista sua posição relativa e intermediária (entre as pequenas cidades e as metrópoles regionais), independentemente de sua expressividade político-econômica no contexto hierárquico de uma rede urbana. São noções, portanto, que se diferenciam da noção de cidade média. Esta última leva em conta a importância sub-regional apresentada por uma dada cidade intermediária, ipso facto, pelas fortes centralidades que aí se materializam por meio de fluxos, a ponto de contribuírem significativamente para o ordenamento do espaço 
regional em que se inserem (TRINDADE JR, 2011, p. 3).

Como já foi tratado anteriormente, a mudança de padrão de ocupação e uso do solo amazônico, caracterizado por Porto-Gonçalves (2000) como a mudança de um modelo baseado na relação entre o rio e a floresta, por ele denominado de rio-várzea-floresta, para um modelo baseado na relação entre a estrada e os recursos minerais (estrada - terrafirme, subsolo) trouxe uma forma diversificada de produção do espaço. Isso significa dizer que há uma pluralidade de dinâmicas sociais na região que produz uma heterogeneidade no que diz respeito ao processo de produção do espaço. Por assim dizer, por mais que as ideia desenvolvidas por Trindade Jr. (2011) deem conta de uma importante fração da região, não significa afirmar que tais relações sejam equiparadas com as demais cidades. Assim sendo, mesmo que Parintins seja classificada como uma cidade média, ela não possui um dinâmica de produção urbano-regional similar aos das cidades cujas realidades empíricas são divergentes. Isso se dá, justamente porque no bojo de seus processos históricos encontram-se particularidades histórico-geográficas inerentes a seus territórios.

Nesse sentido, em Parintins, cidade localizada à margem direita do rio Amazonas, o processo de produção do espaço obedece a uma lógica diferenciada de produção do espaço, porém, desigual e combinada (CORRÊA, 2007). A relação que Parintins exerce com a rede de cidades dispostas espacialmente em seu entorno não dispõe de uma mesma intensidade em relação, por exemplo, às cidades médias da Amazônia Oriental. Há, assim, uma dinâmica peculiar que lhe confere características específicas de uma cidade média no Amazonas, fazendo com que o conceito de cidade média, já arrolado em outras linhas aqui, não seja suficiente para entender sua dinâmica intraurbana e sua relação com a 
região. Por conta disso, Schor, Costa e Oliveira (2009) preferem denominála como uma cidade média com dinâmica econômica externa, pois

tem importância na rede por sua inserção em uma dinâmica econômica externa, os vínculos com as demais cidades na rede não são necessariamente fortes, nem seu desenvolvimento econômico implicará um desenvolvimento regional significativo, pois a atividade econômica responsável pelo seu dinamismo não agrega valor nem no local nem regionalmente (SCHOR; COSTA; OLIVEIRA, 2009, p. 43).

Essa tipologia urbana criada pelos autores permite com que se faça uma perquirição de por que Parintins ser uma cidade média. As atividades que envolvem a dinâmica econômica externa estão relacionadas por um lado com relativa polarização de serviços como do tipo: bancários, comércios e atividade portuária de pequeno porte. As cidades localizadas na calha do rio Amazonas e que, de certa forma, conformam-se em uma área de influência, são razoavelmente polarizadas por Parintins. Exemplo disso é a presença de agências bancárias na cidade. O rio, assim, é o elo com as cidades mais próximas. Essas poucas atividades econômicas, em que não sustentam um forte dinamismo interno acabam por influenciar uma mobilidade de serviços e de pessoas que se encontram em cidades localizadas no estado do Pará, sobretudo aquelas que fazem fronteiras com o estado do Amazonas.

Por outro lado, a função de cidade média de Parintins está muito mais voltada para uma centralidade econômica advinda do Festival Folclórico, onde a disputa entre as agremiações do Boi Garantido e do Boi Caprichoso se faz presente em um curto, porém, intenso período do ano. As dinâmicas arroladas se caracterizam mais pelas relações exógenas ao território intra-urbano. Nesse sentido, a ideia desenvolvida por Schor, Costa e Oliveira (2009) tem aplicabilidade, pois Parintins passa a ser um nó importante na rede urbana do Amazonas. É nesse momento, também, que há uma verdadeira visibilidade da cidade e da região para o mundo, o que 
termina por extravasar o território. Se antes as atividades econômicas não conseguiam agregar valor interno, nesse momento, a intensidade de usos do espaço urbano faz com que a conectividade espacial seja dada em escalas diferentes, porém complementares (o local e o global). Pode-se dizer que, associada à centralidade econômica e política de uma cidade média, existe uma forte demanda cultural que impulsiona os dois primeiros elementos, e, com isso, há um relativo posicionamento na rede urbana.

Esse processo intenso de recondicionamento das atividades econômico-culturais ocorridas em Parintins está ligado a uma concepção de turismo global, típica desta atividade: a de se apropriar dos espaços e implantar neles uma lógica de acumulação de capital de forma homogênea. Contudo, não se pode pensar essa ideia sem antes entender que a reprodução da atividade turística (por conta de ser uma atividade social) é uma atividade que tem o espaço como condição, como suporte para sua realização e como produto dessas mesmas ações desenvolvidas.

\section{A produção do espaço turístico: o debate necessário para o entendimento da rede urbana.}

A discussão que envolve a distribuição de hotéis em uma cidade se dá pela necessidade dos fluxos dessa natureza. No entanto, independente de seu volume ou qualidade de distribuição desses verdadeiros equipamentos urbanos (SANTOS; SILVEIRA, 2001) em um dado espaço, trata-se da própria produção do espaço que, aqui, está submetido aos ensejos da atividade turística. Esta última, por sinal, é aquela que promove o desprendimento de um trabalho dito "sistemático" ou rotineiro (opondose ao trabalho que tem fins lucrativos) conjuntamente com as atividades de lazeriv . Sendo assim, não é excesso afirmar que o turismo é uma atividade que além de consumir espaços, produz espaços, e que possui sujeitos com funções específicas dentro de uma divisão social do trabalho. Assim, a 
afirmação teórica do turismo e, por conseguinte, da produção do espaço turístico se faz "no sólo para satisfacer la necesidad del saber teórico del estudioso, sino también para contribuir a sus intentos para resolver los problemas y oportunidades que se apresentan em la práctica” (MOLINA, 1991, p. 7). Essa situação torna-se emblemática, pois pode ajudar a entender o processo de distribuição da rede hoteleira em Parintins e como esta contribui para a formação da rede urbana do Amazonas.

As mais recentes discussões sobre turismo têm afirmado ad nauseam, que antes de ser uma prática econômica, o turismo é uma prática social. Alguns exemplos podem ser encontrados em Cruz (2000, 2001), Rodrigues (1999) Machado (2007) e Serra (2007). Tal afirmação conduz a uma outra: a de que as práticas sociais turísticas deixam marcas expressivas no espaço mediante o uso desse. Nessa condição, com o avançar do tempo, a prática turística leva, inevitavelmente, à (re)produção de espaços (LEFÉBVRE, 1976). As marcas deixadas pelos anteriores, além de serem condições para outras, terminam por ser base das construções de novos objetos espaciais que os turistas criam ao se reproduzirem espacialmente.

Os objetos espaciais turísticos são obviamente pertencentes às paisagens do lugar, chegando até mesmo a ser a representação de cidade de vários desses lugares. Exemplos mais comuns são a torre Eiffel em Paris, Estátua da Liberdade em Nova York, Cristo Redentor no Rio de Janeiro ou o Teatro Amazonas, em Manaus. Devido a sua magnitude, tais objetos ganharam outras funções a partir do momento em que se percebeu que eles não eram meras próteses espaciais, mas que são integrantes das representações simbólicas das paisagens de um referido espaço.

As práticas culturais realizadas pelos sujeitos estimulam cada vez mais a importância dos objetos espaciais dispostos no espaço. Ainda assim, não se pode deixar de entender que as atividades turísticas procuram contemplar exatamente o que há de "cultural" em lugares diferentes. É nesse sentido que o turismo reflete, necessariamente, o que os espaços 
culturais produzem de novo ou de "diferente". Daí o encanto do turista com as novas paisagens, diferentes daquelas produzidas em seu cotidiano. Dessa forma, pela atividade turística, há uma apropriação das culturas manifestadas no lugar. É nesse momento que se revelam uma dada funcionalidade aos objetos culturais criados pela sociedade, permitindo um fluxo de pessoas com o interesse de visitar os chamados pontos turísticos.

Essa situação é bem aplicável em Parintins quando da realização anual de seu festival. A lógica da apropriação do turismo se dá de uma forma paradoxal, onde há uma estrutura majoritária e homogênea, em que o escopo é a acumulação de riqueza a partir do consumo das manifestações socioculturais. Por outro lado, sendo complementar a essa ação, tal apropriação se dá a partir do "singular". Nesse sentido, tal significado encontra-se na disputa entre o Boi Caprichoso e o Boi Garantido. A disputa das duas agremiações revela o que há de mais particular da região amazônica e de singular da cidade de Parintins. As histórias "cantadas" (ou, especificamente, entoadas) revelam o algo crucial para a apropriação turística. Isso se torna mais forte por conta do terroir. Ou seja, a manifestação folclórica de Parintins não seria a mesma se não fosse à cidade em questão. Harvey (2005) alerta, de forma interessante que a cultura torna-se condição de mercadoria e esses elementos se harmonizam de forma específica. No caso do festival folclórico, tal situação é perceptível de acordo com essa lógica.

Nesse sentido, ainda se apropriando das ideias de Harvey (2005), não é uma condição de cidade média que instaura Parintins dentro de um cenário propício para a reprodução da atividade turística, mas, antes disso, os "marcos simbólicos" dispostos na história (tempo) e no espaço geográfico da cidade. Tais marcos são essenciais para a reprodução do capital, a qual o autor associa, especificamente (para esta relação) à renda monopolista. Essas podem ser traduzidas, no caso de Parintins, como os hotéis na cidade. Porém, é importante que se registre que esses últimos não 
estão inseridos dentro de grandes cadeias hoteleiras globais, mas, possuem, igualmente, o mesmo objetivo que os grandes hotéis: o da acumulação de capital.

Assim, a rede hoteleira, sendo aqui considerada como parte integrante de um sistema de objetos seria um verdadeiro vazio se não fossem as atividades humanas empregadas nela. Os funcionários, bem como os turistas, ao se movimentarem na condição de fluxo de pessoas permitem entender a sugestão oferecida por Santos (2004) de que a atividade humana é que marca o espaço, sendo este último condição para novas relações sociais futuras.

\section{A rede hoteleira em Parintins e sua significância para a cidade média}

A busca pelas informações concernentes à rede hoteleira em Parintins foi feita a partir de uma sistematização de um trabalho de campo realizado no mês de fevereiro de 2009. A intenção era de entender como o processo de consolidação do Polo Industrial de Manaus afetaria a organização interna da cidade e desta com a região e o estado. O processo de construção do trabalho de campo teve como ponto de partida a aplicação do manual da Rede de Cidades Médias - RECIME - a partir disso, a releitura do manual foi feita de acordo com a realidade da cidade, apontando para as similaridades e/ ou divergências.

Como o manual é dividido por "eixos" e, consecutivamente, por "variáveis", compondo um todo, o trabalho de campo seguiu uma sequência onde as variáveis aplicáveis deveriam ter um tema aproximado ou correlacionado à atividade turística em Parintins. Sendo assim, o "Eixo III" que é composto pelos "Equipamentos e Infra-estruturas", tornou-se o ponto de partida para a averiguação dos itens arrolados no manual. Especificamente, a variável n. 19 que se intitula "hotéis de redes nacionais e 
internacionais" revelou-se como o centro de difusão das ideias concernentes ao trabalho.

De fato, ao se pensar a relação entre o espaço concebido (campo das ideias, das racionalidades) e o espaço percebido (aquele referente a uma intermediação entre a ordem distante e a ordem próxima de acordo com cada representação social), pode-se entender que o Manual poderia ser dispensável, visto a distância explicada entre a produção de um documento - produto de uma realidade - e a cidade de Parintins. Isso se aplicaria na condição de "redes hoteleiras", sendo esta a variável presente no documento. Não há, de acordo com o Manual, uma autêntica rede hoteleira, ou seja, aquelas redes internacionais de hotéis que se agregam em um número não tanto extenso de cadeias, mas, que dominam a grande parte do mercado hoteleiro global. Em Parintins, apresenta-se uma distribuição de leitos sem, necessariamente, estes serem inseridos dentro da classificação de "hotéis".

Sendo assim, o trabalho de campo concentrou-se na busca de "hotéis" presentes no setor urbano da cidade, principalmente aqueles localizados no raio de extensão da festividade, e que estariam nas proximidades das redes de serviços e comércio que a cidade poderia oferecer. Dentro desses espaços, procurou-se saber a quantidade de leitos e a relação custo de hospedagem / temporadas turísticas, sendo a alta temporada o período de realização do festival. A quantidade de hotéis não necessariamente se constituiu um passo importante para a pesquisa, mas, sobretudo, como a rede de hotéis procurava oferecer serviços. Os dados quantitativos e algumas entrevistas com os funcionários, servidores públicos municipais e proprietários revelaram situações importantes para a sistematização do trabalho.

A equipe esteve em seis hotéis diferentes buscando as informações solicitadas pelo Manual. Foi constatada a inexistência de hotéis 
pertencentes à redes nacionais e internacionais. As tabelas abaixo apresentam os dados levantados:

\begin{tabular}{|c|c|c|c|c|}
\hline \multirow{2}{*}{ Hotel } & Baixa Temp. & Festival & \multirow{2}{*}{$\begin{array}{l}\text { Tipos de serviços de } \\
\text { hospedagem }\end{array}$} & \multirow{2}{*}{$\begin{array}{l}\text { Pertence a grupo de } \\
\text { empreendimentos da cidade?Qual? }\end{array}$} \\
\hline & Núm. de empregados & Núm. Empregados & & \\
\hline Amazon River & 30 & 30 & $\begin{array}{l}\text { internet wireless, café da } \\
\text { manhã, almoço, jantar, } \\
\text { auditório (150 pessoas), piscina } \\
\text { (adulto e infantil), } \\
\text { estacionamento, quadra } \\
\text { poliesportiva, bar, loja de } \\
\text { artesanato (durante o festival) }\end{array}$ & $\begin{array}{c}\text { Agências de turismo Selvatur e } \\
\text { Tucanaré tour }\end{array}$ \\
\hline Hotel Avenida & 4 & 8 & $\begin{array}{c}\text { café damanhã, piscina, aluguel } \\
\text { de moto, bar (festival), } \\
\text { translado, estacionamento }\end{array}$ & $\begin{array}{l}\text { Locadora de motos, aluguel de } \\
\text { imóveis }\end{array}$ \\
\hline Hotel Mileniu's & 1 & 5 a 8 & lavanderia, bar, café da manhã & Drogaria, loja de confecções \\
\hline Brito Hotel & 4 & 6 & $\begin{array}{l}\text { internet wireless, café da } \\
\text { manhã, estacionamento. }\end{array}$ & Não \\
\hline Palace Hotel & 3 & 3 & $\begin{array}{l}\text { lavanderia, bar, café da } \\
\text { manhã, translado }\end{array}$ & Não \\
\hline Hotel Parintins & 1 & 3 & café da manhã, lavanderia & Loja de confecções \\
\hline
\end{tabular}

Tabela 1 - Dados dos serviços e número de empregados dos hotéis em Parintins.

Fonte: Trabalho de Campo / NEPECAB, fev/2009.

A distribuição de hotéis na cidade não necessariamente acompanhou a quantidade de elementos exigidos para o conforto de um turista. Alguns estabelecimentos mostravam - em suas fachadas - a classificação de hotel, sem necessariamente se constituírem como tal. Em entrevista, a secretária municipal de turismo de Parintins, Senhora Karla Viana Ferreira, disse que somente dois hotéis poderiam ser classificados nessa categoria: o Hotel Brito e o Amazon River. A tabela acima mostra que há uma discrepância considerável na quantidade e qualidade de serviços oferecidos pelos estabelecimentos. Apenas um deles - Amazon River concentra a maior quantidade de serviços disponíveis para os turistas. Os demais poderiam ser inscritos como estabelecimentos que possuem leitos, ainda que possam disponibilizar alguns serviços. Outro dado importante é que o Hotel Amazon River tem forte vínculo com agências de turismo. Isso pode demonstrar que há um direcionamento do público para o hotel por meio de pacotes de viagens ou de propaganda e marketing. Nesse sentido, pode-se afirmar que apenas um hotel da cidade atua em "rede" com demais 
setores de serviços que nutrem o sistema hoteleiro. Os demais estabelecimentos posicionam-se numa condição de empreendimentos locais, sem um devido alcance e conexão com outras redes de serviços internos e externos à Parintins.

Por outro lado, mesmo mostrando uma diferença considerável no que se refere à quantidade de serviços oferecidos, a rede hoteleira em Parintins converge para mesma direção quando o período do festival se aproxima. Os preços na chamada "alta temporada" apresentam uma elevada variação nas diárias, o que se leva a analisar que a força do Festival Folclórico é condição e produto de uma dinâmica externa à cidade, como dito outrora. A tabela a seguir é esclarecedora para este quesito:

\begin{tabular}{|l|c|c|c|c|c|c|c|}
\hline \multirow{2}{*}{ Hotel } & \multirow{2}{*}{ Número de aptos } & \multirow{2}{*}{ Apto single } & Baixa Temp. & Festival & \multirow{2}{*}{ Apto. duplo } & Baixa Temp. & Festival \\
\cline { 5 - 8 } & & & Diária single & Diária single & & Diária duplo & Diária duplo \\
\hline Amazon River & 61 & 13 & $\mathrm{R} \$ 89$ & $\mathrm{R} \$ 515$ & 16 & $\mathrm{R} \$ 109$ & $\mathrm{R} \$ 1.030$ \\
\hline Hotel Avenida & 26 & 10 & $\mathrm{R} \$ 35$ & $\mathrm{R} \$ 300$ & 10 & $\mathrm{R} \$ 45$ & $\mathrm{R} \$ 375$ \\
\hline Hotel Mileniu's & 22 & 6 & $\mathrm{R} \$ 25,00-35,00$ & $\mathrm{R} \$ 500$ & 4 & $\mathrm{R} \$ 45$ a 60 & $\mathrm{R} \$ 666$ \\
\hline Brito Hotel & 23 & 0 & $\mathrm{R} \$ 30$ & $\mathrm{R} \$ 327$ & 20 & $\mathrm{R} \$ 50$ & $\mathrm{R} \$ 376$ \\
\hline Palace Hotel & 17 & 0 & $\mathrm{R} \$ 0$ & $\mathrm{R} \$ 0$ & 9 & $\mathrm{R} \$ 40$ & $\mathrm{R} \$ 300$ \\
\hline Hotel Parintins & 13 & 4 & $\mathrm{R} \$ 15$ & $\mathrm{R} \$ 167$ & 9 & $\mathrm{R} \$ 30$ & $\mathrm{R} \$ 233$ \\
\hline
\end{tabular}

Tabela 2: Preços de apartamentos duplos e singles em Parintins Fonte: Trabalho de Campo / NEPECAB, fev/2009.

\begin{tabular}{|l|c|c|c|}
\hline \multirow{2}{*}{ Hotel } & \multirow{2}{*}{ Apto triplo } & Baixa Temp. & Festival \\
\cline { 3 - 4 } & & Diária triplo & Diária triplo \\
\hline Amazon River & 32 & $\mathrm{R} \$ 129$ & $\mathrm{R} \$ 557$ \\
\hline Hotel Avenida & 6 & $\mathrm{R} \$ 65$ & $\mathrm{R} \$ 425$ \\
\hline Hotel Mileniu's & 12 & $\mathrm{R} \$ 70$ & $\mathrm{R} \$ 666$ \\
\hline Brito Hotel & 3 & $\mathrm{R} \$ 70$ & $\mathrm{R} \$ 667$ \\
\hline Palace Hotel & 8 & $\mathrm{R} \$ 60$ & $\mathrm{R} \$ 300$ \\
\hline Hotel Parintins & 0 & $\mathrm{R} \$ 0$ & $\mathrm{R} \$ 0$ \\
\hline
\end{tabular}

Tabela 3: Preços de apartamentos triplos em Parintins

Fonte: Trabalho de Campo / NEPECAB, fev/2009.

Os dados acima relatados confirmam uma relação desproporcional que há entre os períodos que antecedem o festival e durante o festival. Esse dado, diga-se de passagem, poderia ser entendido como comum, visto que 
são diversos os lugares em que há um período do ano de maiores fluxos de pessoas ocupantes de leitos distribuídos pelos hotéis. Porém, o que chama atenção é o fato de que são apenas poucos dias do ano em que essa diferença se torna considerável. Mesmo assim, a dinâmica que antecede o festival, ou seja, a preparação para o espetáculo não desconsidera Parintins como cidade média no Amazonas, por ser uma cidade que traz fortes vínculos de centralidade político-cultural, associadas a uma estrutura econômica que está para além do território. É importante considerar que antes da relação econômico-cultural presente na cidade, houve uma produção expressiva da juta, elemento que identificava a economia extrativista da cidade e seus arredores. Atualmente, fora esse período do evento, a economia da cidade é movimentada, em grande parte, pela circulação financeira do funcionalismo público do município e do estado, algo que, também, é realizado em curtos períodos dos meses (no dia de pagamento dos funcionários). Não estando dentro do período do festival, há relativa queda da ocupação dos leitos, algo que pode ser constatado pelo número de empregados na "baixa temporada" (ver tabela 1).

Outro fato constatado está na forma do estabelecimento - sua estética. Esta última não oferece certa padronização dos grandes hotéis e pousadas, típicas dos grandes centros urbanos turísticos. Por outro lado, o que se percebeu foi muito mais uma extensão de outros serviços que não necessariamente representam o setor turístico. A exceção é o Hotel Amazon River. Isso pode ser constatado na organização dos dados tabulados (tabela 1) e nas fotos abaixo: 


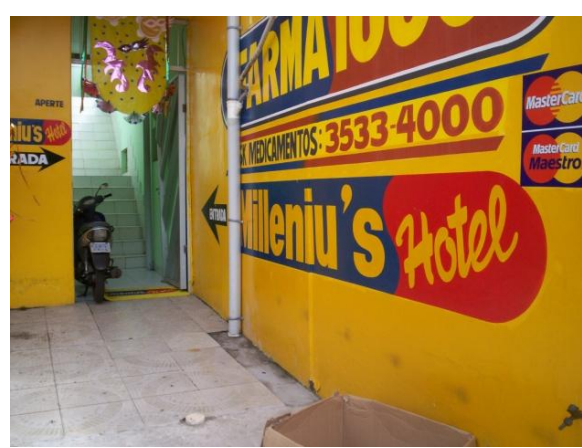

Figura 1: Frente do Hotel Mileni'us

Fonte: Trabalho de Campo/ NEPECAB (fev/ 2009)

Comentário: Nota-se nesse fragmento de fotografia que há uma forma de identificação mista entre serviços. Na parte superior uma identificação de Farmácia; já na parte inferior, a identificação do serviço hoteleiro.

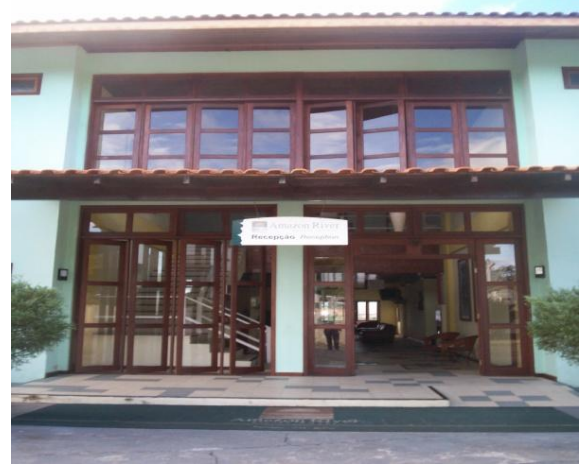

Figura 2: Fachada do Hotel Amazon River

Fonte: Trabalho de Campo/ NEPECAB (fev/ 2009)

Comentário: Nota-se que, diferentemente do hotel anterior, este hotel reproduz uma sofisticação que se torna um de seus diferenciais em relação aos demais presentes na cidade.

Mesmo que a estética e o conteúdo de serviços de um hotel para outro seja diferente, o que, de fato, torna-se marcante é que se consolida a efetiva ocupação desses estabelecimentos nos dias do festival, garantindo, sobretudo, a continuidade dos serviços dessa natureza. Por fim, percebe-se que o número de hotéis pesquisados durante o trabalho de campo em Parintins apresentava uma realidade singular no tocante aos serviços e suas ofertas, o que, pode, em certa medida, ser um dado distinguível dos demais centros urbanos, sobretudo aqueles com perfis de cidade média.

\section{Considerações Finais}

O desafio de se estudar uma cidade média se apresenta como sendo algo importante e interessante em uma região com as dimensões da Amazônia. Esse dado se torna mais instigante por conta das diversas 
realidades que estão contidas na vastidão do território. Parintins, assim, é uma cidade que, mesmo apresentando uma conexão histórica e cultural com outras cidades da região, oferece singularidades bem específicas de seu urbano, obrigando as teorias (que buscam uma padronização nos estudos sobre as cidades médias) a serem repensadas e reaplicadas de acordo com seus interesses e objetivos.

A dinâmica turística é uma atividade na cidade que assume uma expressão notadamente sazonal, o que termina por influenciar na oferta de serviços, como é o caso da rede hoteleira. Em todo caso, essa situação é fundamental para se entender como se apresenta a cidade na rede urbana do estado. Mais precisamente, a atividade turística é responsável, assim, pelo entendimento de que o turismo é uma atividade que tem perfil tipicamente externo à realidade da cidade, ou seja, da forma como é aplicado, sendo ainda, uma manifestação com fortes traços do global dentro de uma realidade local, ocasionando dessa forma, aquilo que Vainer (1986) chama de processo de transescalariedade, onde as manifestações do poder das escalas superiores tendem a homegeneizar as escalas inferiores, a partir de uma ação conjunta, porém com desigualdades socioeconômicas.

No que se refere à rede hoteleira de Parintins, constatou-se que, na verdade, o que se mostra é um processo diferenciado, porém complementar, daquilo que sugere o Manual da Rede de Cidades Médias RECIME -. Mais que isso, o que se percebeu no transcorrer do trabalho de campo é que há uma verdadeira distribuição de estabelecimentos que trabalham com número de leitos na cidade que, por necessidade ou por desconhecimento de seus proprietários, esses estabelecimentos eram intitulados como "Hotéis". Essa distribuição de leitos, por outro lado, garante, sobretudo, certa "perenidade" no uso desse tipo de serviço, visto que, seus ocupantes estariam, dentro dessa lógica, muito mais interessados na contemplação do evento e menos nas condições de estrutura desses fixos espaciais. 
Por fim, percebeu-se que o turismo é uma das atividades sociais na cidade que tem forte relação com uma concepção de economia já consolidada no mercado mundial, ou seja, aquela onde o consumo globalizado das grandes corporações nacionais e internacionais finca raízes no lugar (como é o exemplo de marcas de bebidas, redes bancárias, entre outros). Ao mesmo tempo, a difusão do turismo na cidade ocorre de maneira difusa no que se refere à implantação dos hotéis, principalmente porque não há - em larga escala - uma conectividade das mega-empresas do setor hoteleiro com a cidade, havendo, por outro lado, um incremento local de setores econômicos que trabalham com hotéis locais. Em todo caso, essa é uma condição importante da cidade que a posiciona no posto de uma cidade média no Amazonas.

\section{Notas}

i Trabalho fruto do projeto de pesquisa "O impacto da consolidação do Pólo Industrial de Manaus nas cidades do Amazonas: o caso das cidades de Itacoatiara e Parintins", coordenado pela Prof. Dr ${ }^{\text {a }}$ Tatiana Schor, com apoio do Ministério de Ciência e Tecnologia- MCT / Conselho Nacional de Pesquisa Científica - CNPQ e do Centro de Tecnologia da Amazônia - CT- Amazônia;

ii Professor de Geografia Regional da Faculdade de Geografia da Universidade Federal do Pará, campus de Marabá. Membro do Núcleo de Pesquisas e Estudos das Cidades na Amazônia brasileira - NEPECAB. e-mail: hugoserra@uol.com.br. Tel: (94) 3201 7136; www.ufpa.br.

iii É importante que se diga que neste trabalho de Trindade Jr. (2011) as realidades trabalhadas são as cidades da Amazônia Oriental, mais notadamente as cidades de Santarém (no oeste do Pará) e Marabá (sudeste do Pará). Porém, destacam-se, sobretudo, as relações políticas efetivadas pelos atores sociais presentes nessas cidades e que terminam por influenciar suas unidades sub-regionais: Tapajós para a cidade de Santarém e Carajás para a cidade de Marabá. A ideia, portanto, é evidenciar justamente a apropriação política do território por esses atores, considerados como sujeitos-chave na composição de uma cidade média na Amazônia;

iv É importante que se registre que quaisquer atividades de turismo que sejam classificadas a partir de uma demanda específica, a saber: turismo de compras, turismo de negócios, turismo de saúde, turismo religioso ou até mesmo o controverso turismo cultural (entre outros) só poderão ser encaradas como 
turismo se associarem o trabalho não remunerado pelo sujeito ao lazer, independente das escalas geográficas onde ocorrerem: na cidade de origem do turista ou fora dela;

v Por mais que exista uma diferença na padronização e classificação de hotéis, pousadas, resorts, apart-hotéis ou residências por temporadas, preferiu-se correr o risco de generalizar tal classificação por conta da inviabilidade de dados secundários à época do trabalho de campo (fevereiro de 2009). Nesse sentido, optou-se por uma abordagem mais qualitativa desses espaços do que propriamente quantitativa e taxonômica (aquela que obedece às exigências da ABIH - Associação Brasileira de Indústria de Hotéis).

\section{Referências}

CARLOS, A. O turismo e a produção do não-lugar. In: YÁZIGI, E.; CARLOS, A. \& CRUZ, R. (orgs.). Turismo: espaço, paisagem e cultura. 3. ed. São Paulo: HUCITEC, 2002, p. 25-37.

CORRÊA, R. Construindo o conceito de cidade média. In: SPOSITO, M. (org.). Cidades médias: espaços em transição. São Paulo: Expressão Popular, 2007, p. 23-34.

CRUZ, R. Introdução à geografia do turismo. São Paulo: Roca, 2000.

. Política de turismo e território. São Paulo: Contexto, 2001.

HARVEY, D. A arte da renda: a globalização e transformação da cultura em commodities. In:_. A produção capitalista do espaço. São Paulo: Annablume, 2005, p. 219-240.

LEFEBVRE, H. Espacio y política: el derecho a la ciudad II. Barcelona: Ediciones Península, 1976.

MACHADO, M. Turismo - um conceito socioespacial. IN: SEABRA, G. (org.). Turismo de base local: identidade cultural e desenvolvimento regional. João Pessoa: Editora Universitária - UFPB, 2007, p.65-80.

MOLINA, S. Conceptualización del turismo. Balderas - México: Editorial limusa, 1991.

PORTO-GONÇALVES, C. Amazônia, amazônias. São Paulo: Contexto, 2000.

RODRIGUES, A. Turismo e espaço: rumo a um conbecimento transdisciplinar. 2. ed. São Paulo: HUCITEC, 1999. 
SANTOS, M. A naturez̧a do espaço: técnica e tempo, razãa e emoção. 4.ed. São Paulo: Edusp, 2004.

SANTOS, M.; SILVEIRA, M. Brasil: território e sociedade no início do século XXI. São Paulo: Record, 2001.

SCHOR, T.; COSTA, D.; OLIVEIRA, J. Cidades, rede urbana e desenvolvimento na Amazônia dos grandes rios. In: TRINDADE Jr., S.; CARVAlHO, G.; MOURA, A.; NETO, J. (orgs.). Pequenas e médias cidades na Amarônia brasileira. Belém: FASE/ ICSA-UFPA/ Observatório Comova, 2009, p. 35-58.

SERRA, H. A concepção de turismo e de sua espacialidade no plano de desenvolvimento do turismo do Pará. Dissertação (Mestrado em Geografia). Universidade Federal do Pará/ Programa de Pós-Graduação em Geografia, Belém, 2007.

SPOSITO, M.; ELIAS, D.; SOARES, B.; MAIA, D.; GOMES, E. O estudo das cidades médias brasileiras: uma proposta metodológica. In: SPOSITO, M. (org.). Cidades médias: espaços em transição. São Paulo: Expressão Popular, 2007, p. 35-68.

TRINDADE Jr., S. Cidades médias na Amazônia Oriental: das novas centralidades à fragmentação do território. In: XIV Encontro Nacional da Associação Nacional de Planejamento Urbano e Regional, 2011, Rio de Janeiro. Anais... Rio de Janeiro: ANPUR, 2011, p. 1- 22 (Sessão temática desenvolvimento regional, regionalismo e pactos territoriais).

VAINER, C. B. As escalas do poder e o poder das escalas: o que pode o poder local? Cadernos IPPUR/UFRJ, Rio de Janeiro, v. 1, n. jan./1986, p. 13-32, 1986. 